\title{
Relation Between the School Environment and the Children's Behaviour
}

\author{
Tove Anita Fiskum ${ }^{*}, 1$ and Karl Jacobsen ${ }^{2}$ \\ ${ }^{I}$ Nord-Trøndelag University College, Institute of Teacher Education, Levanger, Norway \\ ${ }^{2}$ Norwegian University of Science and Technology, Institute of Psychology, Trondheim, Norway
}

\begin{abstract}
The aim of this study was to investigate the behavioural outcomes in outdoor education compared with the traditional indoor school condition. 12 children were observed intensively during three days with outdoor education and four days with the indoor condition. Results showed that different organization of the educational environment affected the children's behaviour in various ways, such as levels of physical activity, concentration, being at ease in the situation, verbal and motor agitation, emotional expressions and communication. Outdoor education influenced behavioural changes in a positive direction. During outdoor education, there were only minor differences between leisure time and pedagogical time, with the most desired result in leisure time. In classroom, the difference was enormous, with the most desired results in leisure time.
\end{abstract}

Keywords: Children's environment, outdoor education, physical activity, regulated behaviour, emotion, communication.

\section{INTRODUCTION}

Primary school lessons normally take place in some form of classroom. This normal life in school places large demands on regulation of behaviour. In Norway, however, there are an increasing number of teachers who prefer to vary the educational conditions for their pupils and sometimes take them out of the classroom and do the teaching outdoors. In the general part of the Norwegian curriculum [1] there are a lot of situations which might be used as arguments for bringing the classroom outdoors, e.g. the chapters on the creative human being, the working human being, the social human being, the environmentally aware human being and the integrated human being. In any case, since the second world war it has been possible to find arguments for outdoor education in the curriculum [2]. The changing in the way we live our lives is probably a more important reason for changing our school practice: While children in ancient cultures learned tasks in context, and their problem solving was immediately relevant for them, teaching in school today has become increasingly abstract [3]. Additionally, childhood has moved indoors, and NatureDeficit Disorder is the consequence for many of the children. Nature-Deficit Disorder is not an official diagnosis but a label to explain the loss incurred by the children through losing their contact with nature. As a consequence the possibility of learning from nature and the real world is reduced $[4,5]$.

Research has shown the benefits of taking the pupils out, for example, to a nearby forest or a beach, taking into consideration elements such as the benefits of less demands of action regulation [6], real world experiences [7-9],

*Address correspondence to this author at the Avdeling for lærerutdanning, Røstad, 7600 Levanger, Norway; Tel: +47 740226 35;

E-mail: tove.a.fiskum@hint.no motivation and behavioural benefits $[10,11]$, less crowdedness giving benefits and more enjoyment [12] as well as less aggression and behavioural problems [13, 14], cooperative play and civil behaviour [10, 15, 16], mood benefits [17], which might broaden the scope of attention and action repertoires [18].

Since the schools impose sedentary activity, disruptive behaviour may occur simply because the children need physical activity [3]. Lessons in physical education may be one way to deal with the pupils lack of physical activity, but this does not always promote physical activity [19], even though there is methods to increase the levels of physical activity during physical education [20]. The amount of physical activity in leisure time, may be affected by the surrounding environment i.e. the availability of playgrounds and areas suited for physical activity [21]. Nevertheless, there might be a trend that children spend most of their leisure time without physical activity [22]. Additionally Dale et al. [23] found that children who had restricted possibilities for physical activity during the school day did not compensate by being physically active in their leisure time, while the children who were given the opportunity of physical activity at school, were the most physically active children after school. This implies that the school has some kind of responsibility for children's physical health.

In the natural environment, there are many possibilities that incite the children to activity; it can be considered a kind of enriched environment compared to, for example, a classroom. Gibson [24] calls the options for activities found by the individual in a specific setting 'affordances.' An affordance is something in the environment that offers the person an opportunity to get involved in certain activities. A natural landscape may offer a variety of activity, such as green structures, transportable objects, different landscape elements and diversity of topography that give important potentials for different and versatile play for children [25]. 
The natural environment is a trigger for getting preschool children [26] and children at school [27] into more physical activity.

If schools promote physical activity in children, they thereby give them health benefits in different ways [28-32]. Ways to deal with this challenge are to strive for a big enough schoolyard as well as to avoid overcrowding of the pupils' environment [12,33-35], make it possible to stay in green environments [36] or increase facilities which entice the children into physical activity as well as having adults who supervise them into physical activity $[37,38]$.

Increasing the amount of physical activity is of current interest for many researchers, for instances a new American study made out a bottom-up study in four primary schools, in the aim to make the schools suitable to increase the physical activity, which they did in three of them. Among the factors which made this possible was facility changes, equipment additions or structures recesses [39].

A meta-analysis [40] showed that exercise has a small positive effect on cognition and other research shows that the effect is even higher in children [41]. Both human and nonhuman research support the fact that physical activity, and, especially aerobic fitness training, is a contributor to positive brain function and cognition [42]. Physical activity is an important method in enhancing children's executive functions [43]. Since executive function is related to the set of processes underlying goal-directed behaviour such as planning, inhibitory control, attention flexibility and working memory [44], this may affect all behaviour in children as well as the learning processes. This executive function is related to the process of regulation occurring in the cortex, when action is initiated in the limbic system [45]. This cortical activity works in the same way when regulating behaviour as when regulating emotions $[46,47]$. When this system is not working successfully, unwanted behaviour and emotional reactions will be like the spontaneous reactions in small children. As this system matures throughout childhood, the children become more able to inhibit their emotional tendencies [48]. Playing, especially rough and tumble play, require a lot of social-behavioural and psychological dynamic skills [49]. In play and especially vigorous play, the brain has to regulate and suppress initiations to action from the limbic system, and consequently, this system is being developed through this kind of activity. Giving children greater access to play therefore helps them to regulate impulses better and perhaps even to facilitate brain maturation. This is beneficial for all children, and may even decrease the propagation of ADHD (Attention Deficit Hyperactivity Disorder) [48-51].

Accordingly, it is not surprising that we can see positive academic outcomes from outdoor education $[7,52-54]$ as well as positive behavioural outcomes $[7,10,11,55]$.

The studies and theories presented above give ample evidence for the benefits of physical activities among children for several reasons; the activity could be positive for learning, for health and order and discipline in the classroom, etc. This can easily be made into an argument for adopting outdoor schooling, if we presuppose that this teaching method both contributes to more physical activity and gives the children an enriched environment for practical experiences that later may be translated into an understanding of theory and better motivation for further education. Outdoor education probably influences behaviour and emotions in different ways. There is, however, limited documentation about this effect in outdoor education. If there is such an effect through outdoor education, is it caused by the changed organization of the school day or is it mostly caused by the changed environment they are offering the children? We, therefore, set out to investigate how the children actually behave during outdoor schooling compared to normal indoor school days. To explore this wide area of opportunities, we raised two questions considering the possible behavioural changes that might happen because of outdoor education.

Are there any differences between the days organized as outdoor and indoor education in terms of children's behaviour, such as physical activity, verbal and motor agitation, communication or emotion?

Is the present tested behaviour most influenced by the environment the chid is in or whether it is teaching time or leisure time?

\section{METHOD}

To explore this relatively many different variables and how they might be affected during the whole day, during teaching time and during leisure time, there was made a roughly sort out of categories within the variables, as well as a qualitative study to explore more directly how this may affect the child at school.

\section{Design}

This is a one-group study; a natural ABAB-design with phases guided by the schools ordinary schedule. An ABABdesign is a one-group experimental design were the purpose is to reveal the effects which occur when the intervention is on in condition B and when it is off in condition A. The benefit with this kind of design is the possibility to look at intra-individual differences while manipulating with one variable at time [56, 57], but this design will only fit if the behavioural changes are not permanent [58].

In this study, only few subjects are observed, but with many observations per subject, instead of observing many subjects a few times. In the ABAB-design, the subjects are their own controls. A single AB-design may therefore be classified as a pre-experiment, but an ABAB-design may be classified as a quasi-experiment. If the length of the intervention-phases is randomized, it may even be a true experiment [58].

This ABAB-design involves both a large quantitative study with the variables of verbal and motor agitation, physical activity, communication and emotion, as well as a qualitative part with two pupils. This part is to a wider degree exploring the behaviour within the context. These data are reduced into one ABAB-story for a girl given the fictive name Ida, and for one boy, given the fictive name Frank.

\section{Subjects}

The subjects were recruited from the $5^{\text {th }}$ grade in a primary school in Norway. From a total of 34 children in two 
classes, 31 were given permission from their parents to participate in the study. From this group seven boys and five girls were randomly selected. Their mean age at the beginning of the study was 10 years and 3 months, with a range from 10 years to 10 years and 8 months. The children were in the first semester of their fifth year at school when the study was carried out. All these children were observed in a qualitative way, while one of the girls and one of the boys were randomly chosen to the qualitative part of the research project.

\section{Teaching and Activities}

Observation was obtained in seven days: four days with indoor teaching and three days with outdoor teaching. The plan was to observe four days inside and four days outside, but unfortunately we did not decide or affect the plans for each day. One of the days they decided to play football. This day differed too much in structure and other characteristics to be comparable with the other days and had to be let out. The pupils were familiar with both conditions. During both conditions, they were observed during teaching and during breaks.

During the indoor schooldays, when the children had various academic subjects, they were seated individually or in groups of two and three children. At the end of the day, however, when they were required to focus on their 'weekly work plan', they were allowed to sit in groups of three or more children together.

The three days with outdoor education started with one lesson in the classroom. Afterwards they walked to one of their outdoor education areas. Those areas have a lean-to, a fireplace and an outdoor lavatory. Two of these days were like the outdoor education practice they were most used to; they stayed at the place, had some time for free play, ate lunch and participated in various outdoor academic lessons led by the teachers. One of the days was a bit different, as the children were divided into mixed age groups (pupils from 5th, 6th and 7th grade) and they attended other places than the places they would usually go to.

\section{Time Schedule}

In order to quantify the children's behaviour, they were observed under two different conditions, for seven days altogether.

The school started for all conditions at 8.30 and lasted until 14.00. For indoor school, the children were observed after this time schedule 09.15-09.45, 10.15-11.00, 11.2012.20 and 12.30-13.00, which ensured that the observations covered different academic subjects and at least one recess every day.

The observations for both conditions were done in sections. Each section involved a series of three minutes of quantified observations (involving 13 observation points with 15-second intervals) for each child and two minutes available for writing qualitative notes for the same child. After 5 minutes with this focus on one child, the observer started to focus on another child for five minutes and thereafter for the third child for five minutes. One section like this lasted for 15 minutes.
For each observation point, the observer made notes about the child's verbal and motor behaviour, the child's degree of physical activity, the child's mood and whether the child communicated with someone. If the child was speaking to someone, notes were taken as to whether the communication was positive or negative.

For outdoor education, the observation started as soon as the group had reached the particular outdoor area. Under these two conditions, observations were made continuously in order to get the same amount of data as collected during indoor condition.

The goal was to observe each child in 11-sections per day. Since the pupils were not observed during the walking session before and after outdoor education, and because sometimes extra time was needed to localize the child, this number of sections was not achieved for every child during these days.

The structure for indoor schooldays was 45 minutes with learning sections, followed by 15 minutes leisure time, except for the lunch that lasted about 30 minutes, as well as they once a while was getting some extra leisure time to play outside. The structure during outdoor some time with free activities before lunch. These activities often where indirect guided into academic topics, but it was all voluntary and it is therefore in the observations noted as leisure time. After lunch they had a time schedule with approximately 45 minutes of teaching and 15 minutes of leisure time.

\section{Observations}

The observations were done by four trained persons each day, each observer collecting data for three children. All observers were students of pedagogy at a university college. The number of observations for each subject across conditions, observer and gender, is shown in Table 1.

Table 1. Subjects, Observers and the Distribution of Observations

\begin{tabular}{|c|c|c|c|c|c|}
\hline \multirow{2}{*}{ Subject } & \multirow{2}{*}{ Sex } & \multirow{2}{*}{ Observer } & \multicolumn{3}{|c|}{ Number of Observations } \\
\cline { 4 - 6 } & & & Outdoor & Traditional & Total \\
\hline \hline 1 & M & 1 & 403 & 571 & 974 \\
\hline 2 & M & 2 & 390 & 572 & 962 \\
\hline 3 & M & 1 & 403 & 573 & 976 \\
\hline 4 & F & 2 & 247 & 559 & 806 \\
\hline 5 & F & 1 & 260 & 572 & 832 \\
\hline 6 & M & 2 & 390 & 546 & 936 \\
\hline 7 & M & 4 & 325 & 572 & 897 \\
\hline 8 & F & 3 & 390 & 559 & 949 \\
\hline 9 & F & 3 & 390 & 571 & 961 \\
\hline 10 & M & 4 & 338 & 572 & 910 \\
\hline 11 & F & 3 & 247 & 560 & 807 \\
\hline 12 & M & 4 & 325 & 572 & 897 \\
\hline Total & & & 4108 & 6799 & 10907 \\
\hline & & & & & \\
\hline
\end{tabular}




\section{Scales}

To quantify the variables, different scales was used. This observation scale is a kind of general classification with the aim of exploring the field. In this roughly categorizing of the activities, one of the variables, physical activity is divided in 1-3, because there cannot be any absolute absence of physical activity. The variables of agitation starts with zero, because there might be an absent of agitation, and the scores 1-3 deals with the degree of agitation. Emotion is divided into five categories; strongly negative, moderate negative, neutral, moderate positive and strong positive.

For each of the variables, each level was characterized as a guide for the observers as follows:

\section{Observation of the Degree of Physical Activity}

To measure the physical activity of the children, a 3point scale was used: Score 1 (low activity) was given when the child was either sitting or standing or was doing some small physical activity like walking slowly. Score 2 (medium activity) was given if the child was participating in a kind of activity like walking fast. In score 3 (high activity), the child was quite active and was e.g. running or participating in activities more demanding than walking, e.g. throwing and catching a ball, or if the child was running a lot, climbing or doing activities which would usually break sweat after a short time.

\section{Observation of Verbal Agitation}

The scores can be characterized as follows: Scores 0: no verbal agitation at all.

Score 1(low degree of verbal agitation) should be given when the child was talking about other subjects than the task, but not disturbing others nearby. Score 2 (medium degree of verbal agitation) should be given when the child was talking about other things than the teaching to a degree that was disturbing for the others. If the child was bickering or showing any kind of aggression, this score should also be given. Score 3 (high degree of verbal agitation) should be given if the child had a lot of foul language that was considered to disturb the others a lot. If the child e.g. was yelling, making noises to disturb the others, hurting others or quarrelling with others, this score was also given.

\section{Observation of Motor Agitation}

The scores can be characterized as follows: Scores 0: no motor agitation at all.

Score 1 (low degree of motor agitation) should for example be given if the pupil was working with other subjects than the object of the teaching or if the pupil is not working successfully in relation to what the environmental situation requires. Score 2 (medium degree of motor agitation) should be given if the child was disturbing the others with his/her actions. If the child was seeking amusement or was sitting in other places than expected, he/she should also be given score 2 . Score 3 (high degree of motor agitation) should be given when the child was walking around without doing anything connected to the teaching. This score should also be given if the child was grabbing things from other pupils, was obviously creating a disturbance with his/her motor activity, showed aggression to others or was completely diverted from what the others are doing. Outside, this score was given when the child was not doing what the environmental situation required and, at the same time, was disturbing the others a lot and perhaps teasing or threatening the others with his/her motor activity.

\section{Observing Emotion}

Emotion is divided into a 5-point scale ranging from obvious discouragement to joy and laughter. Score 1: (strong negative emotion) should be given when the child is obviously showing discouragement e.g. by crying or almost crying or being obviously negative. Score 2: (moderate negative emotion) is a less discouraged level, e.g. showing obvious signs of boredom. Score 3: (the neutral emotion) is the neutral level, showing neither obvious discouragement nor obvious joy. Score 4: (moderate positive emotion) deals with some kind of joy. It is when the child smiles without laughing really joyfully, or when the child is really engaged in an activity and shows enthusiastic eagerness e.g. stepping out of reality and taking a role in the play. Score 5: (strong positive emotion) is only given when it is possible to hear the child laugh.

\section{Observing Communication}

Whether the child was communicating verbally with someone was noted. If there was any kind of communication, it was noted whether it was positive or negative. All communication that was not negative was interpreted as positive.

\section{Qualitative Observations}

For each section of observations, the observer was told to write something about the child in the situation and the demands and activity in the section.

\section{Reliability}

As a preparation for the study, the four observers were trained in a process that involved:(1) introduction and exemplifications of the score-criteria, (2) parallel observations, (3) discussions to obtain common understandings. This procedure was repeated four times, and then the observers where almost identical. During the observation days checkpoints where made to make sure that inter-rater reliability still was high $(97,9 \%)$. This high percent of reliability is not surprising considering the relatively rough categories.

\section{Analysis}

SPSS version 19.00 is used to make the t-test for independent sample and to make the descriptive data of the ABAB-design.

For the qualitative data, the first step was to write something for each section. When the qualitative notes are looked at together with all the observations in relation to each other, it gives abroad sample of information for each child. In the next step, each section-description is interpreted and concentrated: first in a wide description for each day and thereafter into single stories for each of the days where the most typical and the most specific happenings and behaviour were recorded. 
Table 2. Relationship Between Outdoor Education and Indoor Education

\begin{tabular}{|c|c|c|c|c|c|c|c|}
\hline \multirow{2}{*}{ Variable } & \multirow{2}{*}{$\begin{array}{l}\text { Teaching } \\
\text { Method }\end{array}$} & \multicolumn{2}{|c|}{ Teaching Time and Leisure Time } & \multicolumn{2}{|c|}{ Leisure Time } & \multicolumn{2}{|c|}{ Teaching Time } \\
\hline & & Mean & $p$ & Mean & $p$ & Mean & $p$ \\
\hline Motor agitation & $\begin{array}{l}\text { Outdoor } \\
\text { Indoor }\end{array}$ & $\begin{array}{l}0.039 \\
0.106\end{array}$ & $0.000^{*}$ & $\begin{array}{l}0.030 \\
0.092\end{array}$ & $0.000 *$ & $\begin{array}{l}0.046 \\
0.108\end{array}$ & $0.000 *$ \\
\hline Verbal agitation & $\begin{array}{l}\text { Outdoor } \\
\text { Indoor }\end{array}$ & $\begin{array}{l}0.027 \\
0.105\end{array}$ & $0.000^{*}$ & $\begin{array}{l}0.151 \\
0.075\end{array}$ & $0.000^{*}$ & $\begin{array}{l}0.040 \\
0.110\end{array}$ & $0.000^{*}$ \\
\hline Neutral emotion & $\begin{array}{l}\text { Outdoor } \\
\text { Indoor }\end{array}$ & $\begin{array}{l}0.662 \\
0.853\end{array}$ & $0.000^{*}$ & $\begin{array}{l}0.596 \\
0.612\end{array}$ & 0.408 & $\begin{array}{l}0.712 \\
0.893\end{array}$ & $0.000 *$ \\
\hline Positive communication & $\begin{array}{l}\text { Outdoor } \\
\text { Indoor }\end{array}$ & $\begin{array}{l}0.456 \\
0.177\end{array}$ & $0.000^{*}$ & $\begin{array}{l}0.532 \\
0.394\end{array}$ & $0.000 *$ & $\begin{array}{l}0.399 \\
0.141\end{array}$ & $0.000 *$ \\
\hline Negative communication & $\begin{array}{l}\text { Outdoor } \\
\text { Indoor }\end{array}$ & $\begin{array}{l}0.027 \\
0.024\end{array}$ & 0.415 & $\begin{array}{l}0.026 \\
0.031\end{array}$ & 0.415 & $\begin{array}{l}0.028 \\
0.023\end{array}$ & 0.230 \\
\hline Physical activity & $\begin{array}{l}\text { Outdoor } \\
\text { Indoor }\end{array}$ & $\begin{array}{l}1.430 \\
1.083\end{array}$ & $0.000^{*}$ & $\begin{array}{l}1.404 \\
1.532\end{array}$ & $0.000^{*}$ & $\begin{array}{l}1.449 \\
1.007\end{array}$ & $0.000^{*}$ \\
\hline
\end{tabular}

*Significant 0.001 .

T-test for independent samples for all observations during the day, for the leisuretime observations and for the teaching time observations. The variables of emotion and communication, is dichotomized; neutral emotion is given value 1 and the other emotions is given value 0 , positive communication is given value 1 and the rest of the observations (with negative or none communication) is given score 0 in the variable of positive communication, while it for the variable of negative communication is the negative communication which is given value 1 .

\section{RESULTS}

The first step in analysing the quantitative data is an t-test for independent samples for the whole conditions first, and thereafter separately for the leisure time and for the pedagogical time (see Table 2).

Considering the quantitative date, for all variables there is a trend that pedagogical time follows the pattern for the whole day, and the leisure time, which has fewer observations, has another pattern.

\section{Physical Activity}

Independent of school organization, the results from observations show that children spend most of their time with only a small occurrence of high physical activity, but outdoor education is able to increase the amount of time spent in high physical activity as well as the average for physical activity during the day (see Fig. 1).

For outdoor education, there is hardly any difference between the results in leisure time and in pedagogical time. For the indoor condition, the difference is enormous; there is much more inactivity during pedagogical time and much more activity during leisure time. Since breaks only are a small part of the days at school and of the observations in this study, this hardly affects the results for the whole day.

\section{Motor Agitation}

The results for motor agitation are shown in Fig. (2). This shows a main pattern of lower levels of motor agitation

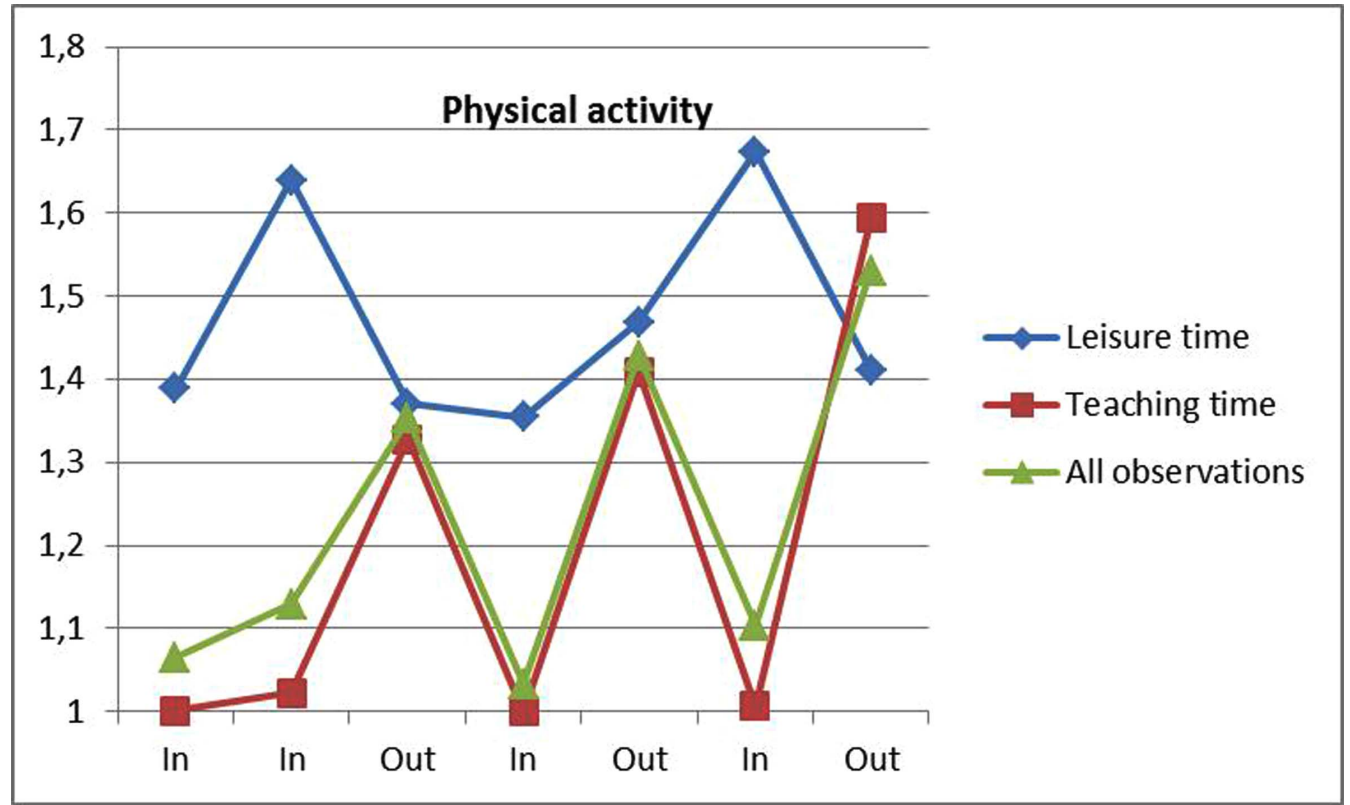

Fig. (1). Average levels of physical activity during the days with observations. Low levels of physical activity is given score 1, middle levels of physical acitivty is given score 2 and high levels of physical activity is given score 3 . 


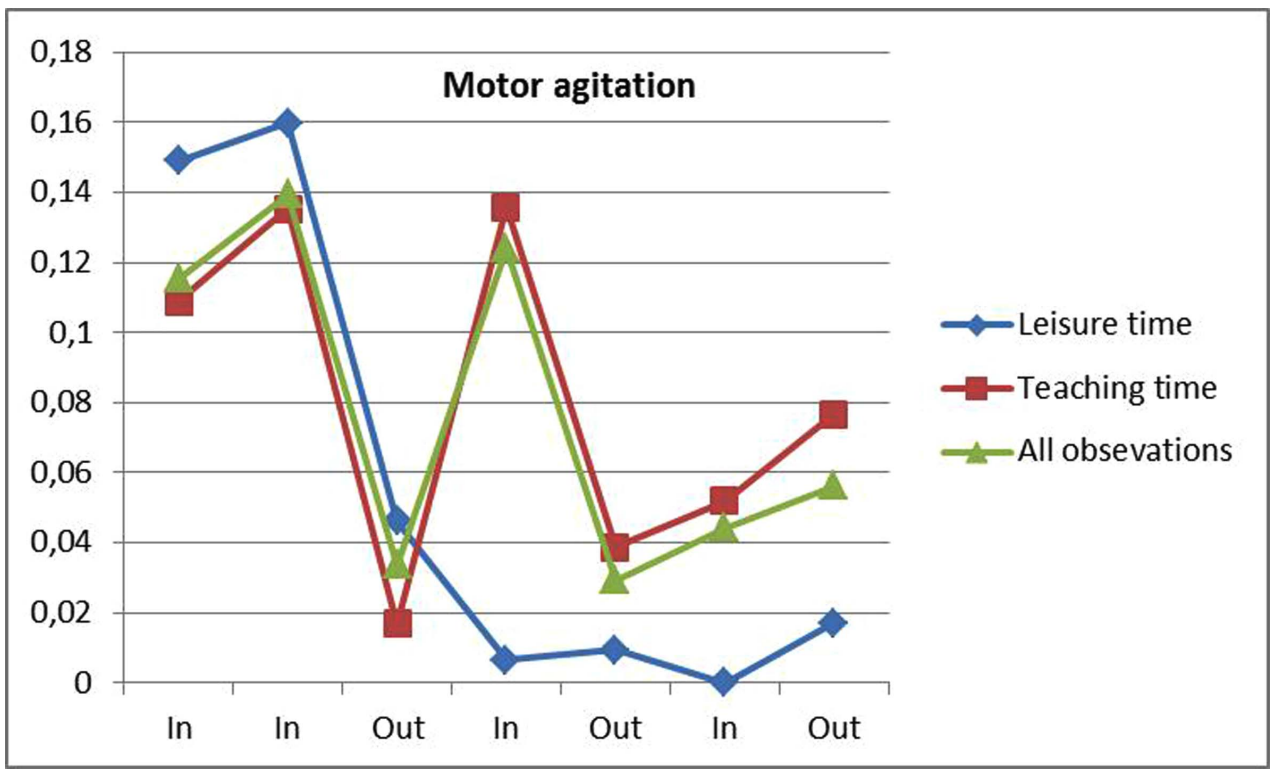

Fig. (2). Average levels of motor agitation during the days with observations. No agitation is given score 0 , low levels of agitation is given score 1 , middle levels of agitation is given score 2 and high levels of agitation is given score 3 .

during two of the outdoor education days and some lower level for the last outdoor education day and the last indoor education day. Average levels of motor agitation are remarkably higher during three of the indoor education days. Motor agitation during leisure time shows another pattern: For four of the days the average amount of motor agitation is lower during leisure time compared with pedagogical time. For two of the days with indoor education the average amount of motor agitation during leisure time is higher compared with pedagogical time. In one of the outdoor education days, the amount is also higher during leisure time.

\section{Verbal Agitation}

The main pattern for verbal agitation is a lower level of agitation during outdoor education compared with indoor education (see Fig. 3). Indoor education shows an irregular result, with a peak on the third day with indoor education and a much lower level on the last day with indoor education.

For leisure time the pattern is different: There might be a pattern of lower levels during outdoor education, except for the last day of indoor education, which has the lowest levels of all days. The verbal agitation during leisure time is mostly at lower levels compared with pedagogic time, but there is an exception on the first two days with indoor education where the levels are higher during leisure time.

\section{Emotion}

For emotion, the majority of observations are placed at the neutral level. Therefore, the result is focused on the

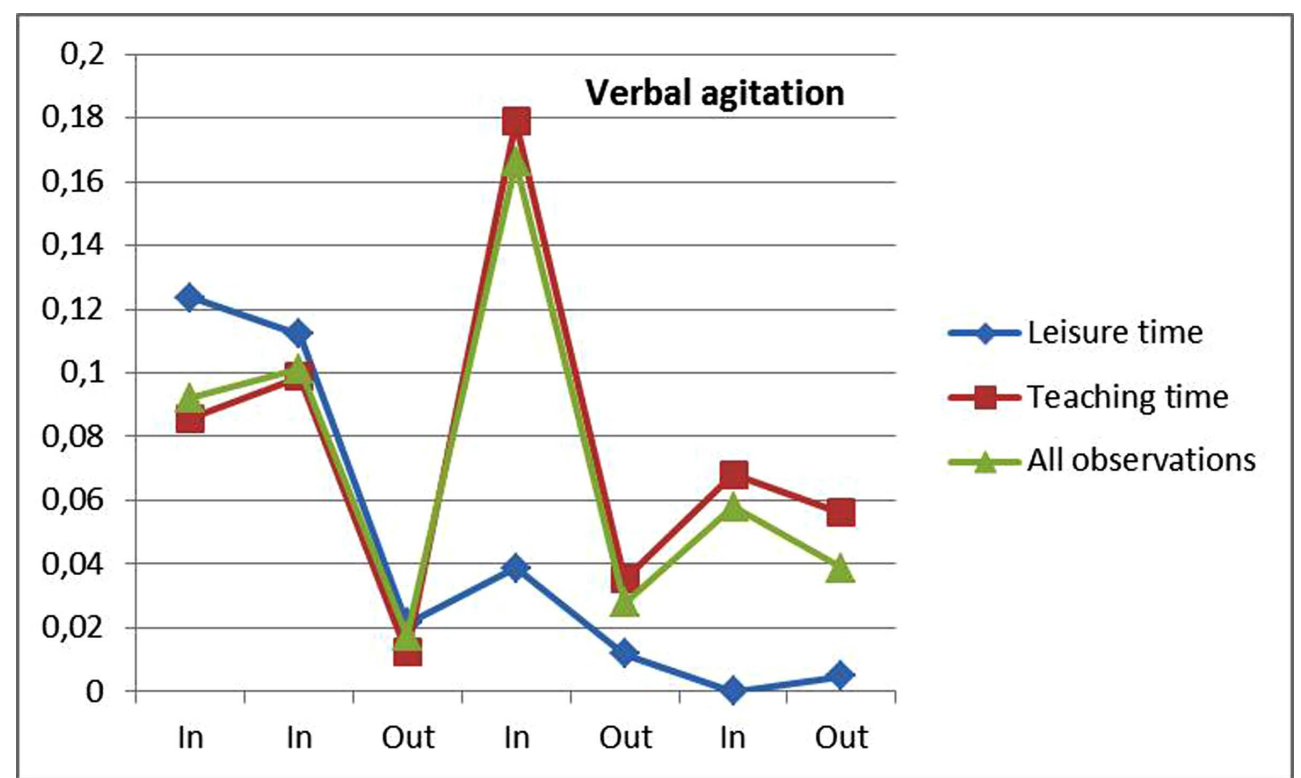

Fig. (3). Average levels of verbal agitation during the days with observations. No agitation is given score 0 , low levels of agitation is given score 1 , middle levels of agitation is given score 2 and high levels of agitation is given score 3 . 


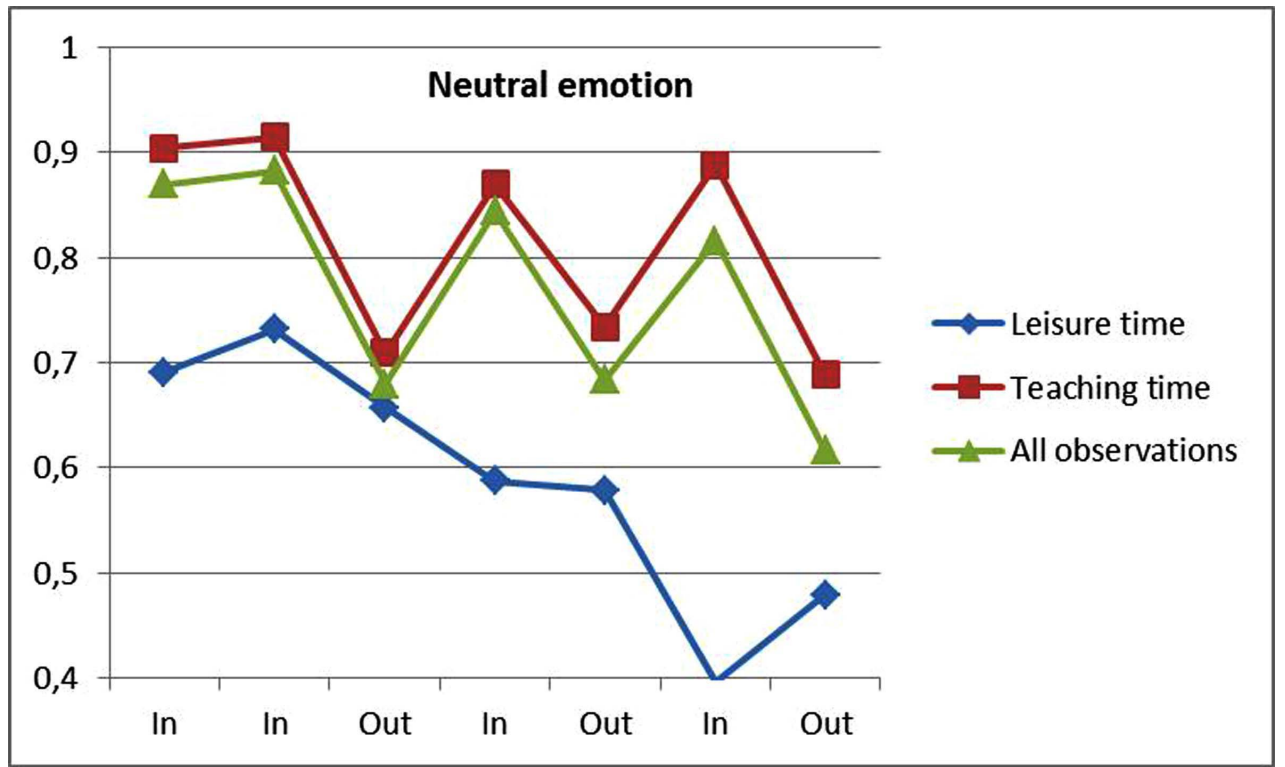

Fig. (4). Average levels of neutral emotions during the days with observations. Neutral emotion is given score 1 and other emotions is given score 0 .

amount of neutral emotions. There is however, some variability about the amount of observations placed at neutral level for each day and for the conditions leisure time and pedagogical time. Fig. (4) shows a pattern of lower levels of neutral emotions during outdoor education days. For all school days, teaching time has an average higher amount of neutral emotion compared with leisure time. The pattern for leisure time is very different from teaching time: It is not possible to see a pattern between the two school conditions, since indoor education both has the day with the highest and the lowest level. Outdoor education does have the smallest difference between teaching time and leisure time.

\section{Communication}

The amount of positive communication shows a clear pattern with higher average levels of communication during outdoor education (see Fig. 5). The average amount of positive communication during leisure time is at a higher level on all days, and at the same time follows almost the same pattern, except in day four. The difference between teaching time and leisure time is smaller for the outdoor education days.

Negative communication is only observed in a very minor occurrence (see Fig. 6), and the pattern is not clear. It shows a lower level during three days with indoor education and one with outdoor education. The absolute highest amount of negative communication is observed during an indoor education day with one day of outdoor education right after. The average amount during pedagogical time follows the same pattern as the average for the whole day. The average amount of negative communication during leisure time shows a higher level during the three first days, while the level is lower during two days with indoor education and two days with outdoor education.

The statistical analyses showing the trends for changing during the changing conditions in school is an indicator about how we should suppose outdoor education might work on the class of pupils. Anyway, in school there is the individuals we meet, as well as we meet them in situations day to day. The qualitative date showing the day-to-day life in school for two randomly chosen pupils is therefore shown in Frame 1 and Frame 2.

\section{DISCUSSION}

The aim of this study is to explore the relationship between outdoor education and indoor education considering a wide range of variables. The results from both the t-test and the main pattern of the curves in the figures, as well as the examples from the two pupils show that outdoor education has more benefits than learning biology and getting fresh air in the lungs. Outdoor education has a positive influence on the children's behaviour as it increases their levels of physical activity, decreases verbal and motor agitation, increases the amount of positive communication and elicits more joy and laughter as well as broadening the repertoire of emotions.

\section{Physical Activity}

Compared with the indoor school setting, outdoor education increases the children's level of physical activity. It is not surprising that the children are less physically active on the indoor days. They are supposed to sit in the classroom during the lessons and the recesses are the only time they are allowed to be physically active. Days with outdoor education include time to play in the natural environment which could well provide scope for the children's physical activity [24, $25,36,59]$, but these days include pedagogical time too, and these activities do not always tend to elicit physical activity. In the three days with outdoor education observed in this project, the level of physical activity during pedagogical time is almost as high as during leisure time. The difference between the conditions during pedagogical time is therefore what we would expect since traditional pedagogic time usually involves sitting. The difference in the leisure time is more interesting: It looks as if the children, in some way, are trying to compensate for the inactivity during the pedagogic time in the indoor condition, which could be a signal for 


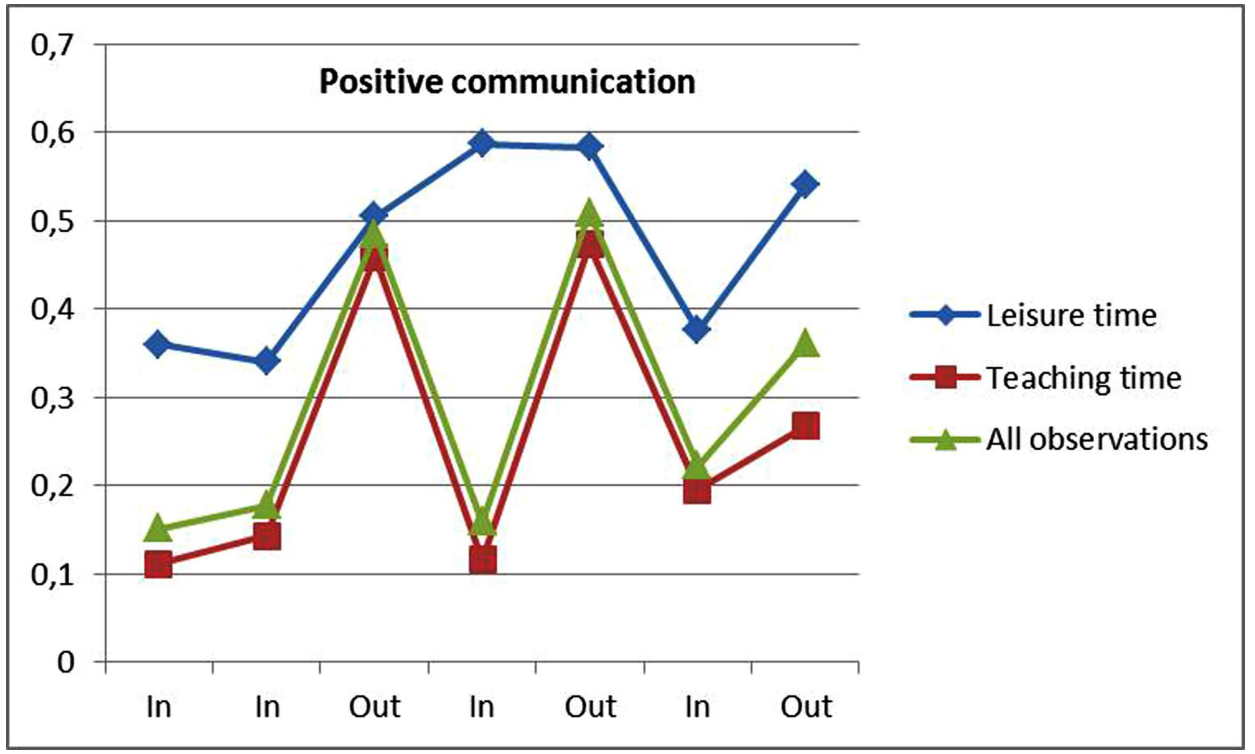

Fig. (5). Average levels of positive communications during the days with observations. Positive communications are given score 1 and obsevrations with no communications or negative commuications are given score 0 .

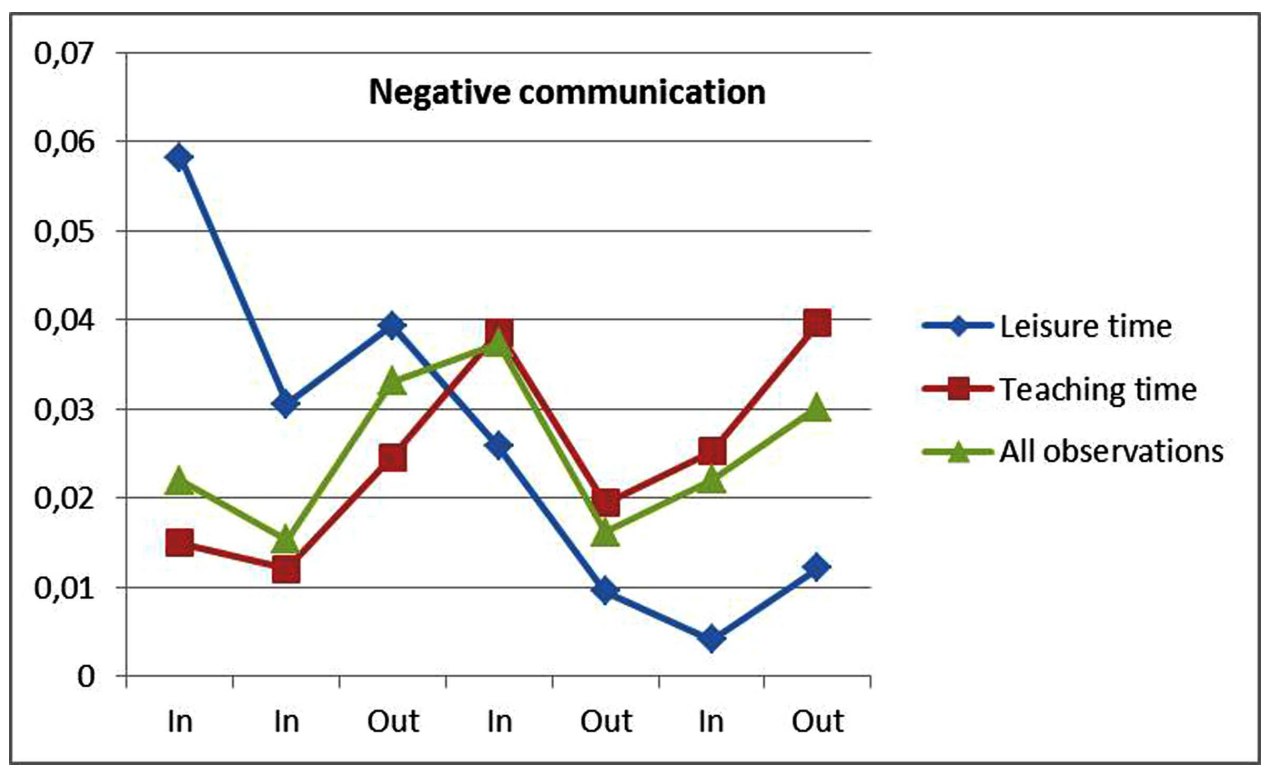

Fig. (6). Average levels of negative communications during the days with observations. Negative communications are given score 1 and observations with no communications or positive commuications are given score 0 .

children's real need for physical activity (see e.g. [3]). These findings do not support the research, which found a lack of compensation after inactivity [23]. The activity in leisure time in this research is only in some of the breaks between the lessons, and may therefore give another picture than the study by Dale, Corbin and Dale [23], which gives a picture of the activity after school. The wide and relatively unlimited area the children use in the leisure time during the indoor condition may be another explanation for their relatively high levels of physical activity. This is in accordance with the study by Ozdemir and Yilmaz [12] which found a connection between the size of the schoolyard and children's BMI, assuming the physical activity to be the mediating variable as well as the study made by Kulinna et al. [39] which managed to increase the levels of physical activity with i. e. the variables off facility changing in the schoolyards and equipment additions. The number of observations with a higher level of physical activity is not large enough to influence the whole day percentages, and, consequently, the children's day at school is quite inactive.

For outdoor education, the level of physical activity is almost the same during leisure time as during pedagogic time. This might be the result of some of the pedagogic activities involving physical activity as well as the fact that leisure time observations also involve lunch-time, when children sat down to eat their lunch. Some of the children used a longer time with their lunch at outdoor education, since they had brought some extra food, some biscuits to eat after lunch or some food they wanted to barbecue at the bonfire. 


\section{Frame 1. Ida's Behaviour During the Observation Days}

Day 1: In the lessons, she fiddles frequently and in short periods her concentration slips. When exercises activate her, either with writing or reading together with others, she focuses on task and the restlessness disappears. She is also observed with negative communication to others. Otherwise, she does not talk much during lessons. Emotion is mostly neutral. While eating lunch her interaction with other classmates is negative.

Day 2: When she is frustrated from opposition, she becomes agitated, but when she focuses on the exercises she works successfully. She is mostly quiet, but when the teacher is absent, she talks to another pupil. In the break she plays football, though it looks like she is hurt physically during this game. She then runs inside to loneliness. She appears sad. In the lessons afterwards her sadness continues in a crying period. No talking is observed during this.

Day 3: While walking to the other outdoor area she interacts with her classmates. When they have to wait she communicates both positively and negatively with the others. Once she yells to one of the other pupils. In a break, she hurries to the swing. When making the swing go fast she smiles, but she has no interaction with others during the activity. In another break she crawls under a boat with others and talks and laughs. When working with academic subjects she communicates verbally to others and emotion increases to level 4. Activities that are more practical activate her even more.

Day 4: She has neutral emotion during the day except for a few observations. When starting a new activity she starts quickly and dutifully, but after a while, she is mostly restless and absent minded. She also has negative comments to other pupils. In lectures she participates, puts up her hand to answer questions, and she smiles when she is among those who are to read the text in English. In music they have a practical activity. In this condition she becomes restless and makes negative comments to other pupils, followed by a period of an increased amount of positive behaviour.

Day 5: She is not at school this day.

Day 6: She is at the library together with older helpers. She interacts with others and emotion is positive. Later emotion rises to level four while she reads by herself. In mathematics she is restless but concentrated; she put up her hand to answer questions and she cooperates and works successfully with group exercises. Outside in the break she plays with younger pupils. Then emotion increases in periods but she does not communicate verbally. In a lecture her restlessness increases and she is obviously disturbing the others with her motor activity. Then her concentration decreases and she is disturbing the others with verbal agitation. Emotion is neutral during this. During the lesson where they are supposed to work with their weekly exercises, she sits together with three other pupils. She interacts verbally with them, mostly in a positive way.

Day 7: She is alone at the swing. During swinging her emotion increases. After that, she begins to communicate verbally with others and emotion often rises to level 4 . While waiting to start the academic subjects, she made negative comments to others and joined in a rough and tumble play which develops negatively. At the post with physical education, her level of physical activity increases and her emotion is positive. An incident makes her start to become agitated, followed by a decrease in activity and emotion. When starting with mathematics she seems bored. She is restless and agitated. When the activity is more practical, her activity increases and she communicates verbally to others and her emotion is positive. After a while, her positive behaviour is retained. When academic subjects are finished she does not participate with the others at the beginning, and she only had one negative comment. Then she starts participating in rough and tumble play; physical activity rises, emotion rises to level 4 and 5 and communication increases.

\section{Verbal and Motor Agitation}

The outdoor education had the lowest occurrence of verbal and motor agitation when looking at the whole day. The curves for teaching time followed the curves for the

\section{Frame 2. Frank's Behaviour During the Observation Days}

Day 1: When the class has an academic activity involving competition and/or entertainment, he is eager but restless. Emotion is positive. When the academic activity slows down, he mostly concentrates on task, but in periods, he is restless and absent minded. When they have to wait, he is restless and makes several negative comments to others. When they eat their lunch he talks all the time, his emotion is positive and he is restless in periods. Outside he just looks at something the older boys are doing. He makes negative comments to others and his emotion is neutral.

Day 2: Except for periods with less concentration, he mostly is concentrating on task. He is restless in periods and makes several negative comments to others. His emotion is mostly neutral. During a practical activity, he cooperates with another pupil. He makes several negative comments to a girl next to them. In breaks he plays football or cycles. He mostly plays with high levels of physical activity. In periods, the emotion and the amount of verbal communication are increased. In a period he rides his bicycle in places where he has no permission to cycle.

Day 3: In the beginning he sits alone whittling. Emotion is positive. Another pupil arrives and they interact with each other. An incident makes him show negative behaviour against another pupil near them. Emotion goes back to neutral for a period, before it rises to a positive level again. During the rest of the spare time he talks almost all the time. When they work with academic subjects, he tries to be the leader of the group. He is happy and eager.

Day 4: During the lessons he is often restless and absent minded. Emotion is mostly at neutral level. When they have a practical activity he first works successfully while emotion is at level four and he interacts with other pupils. Then the emotion goes down to neutral, he starts to be restless and absent minded as well as making negative comments to another pupil. In music, the activity is more practical, he is eager to show his competence, and his negative behaviour is absent. When they are going to have a little competition in the English-lesson, he is eager and laughs, but ignores the rules and does not do what he is supposed to. He also made negative comments to another pupil.

Day 5: Emotion is often at level four and five this day. Some negative comments to other pupils and some short periods with restlessness and absent-mindedness are observed, but for most of the time the negative behaviour is absent. While working with academic subjects he tries to take the responsibility of the work in the group. He talks much both during academic subjects and during spare time. In one of the activities, things do not go his way and his emotion goes back to neutral for a while. At the same time, he is restless and interrupts the others with his motor activity.

Day 6: At the beginning they have some library-time together with older pupils. He communicates and cooperates and emotion is at neutral or at positive levels. When having a lecture he is restless and in periods absent minded, while emotion is neutral. When they start with practical activities in the same subject, he is the leader in the group: eager, with positive emotion and an increased amount of communication. In breaks he plays football in the snow, which makes them smile and laugh because of the slippery ground. Physical activity varies between medium and high levels, and in periods he talks to the others. After one of the breaks, he works successfully and concentrates with some exercises, while emotion is neutral.

Day 7: He communicates frequently, and he has an increased level of physical activity and positive emotion while playing in the forest. He leads the work in the group when they have academic subjects in English and Norwegian grammar. His emotion varies between neutral and positive. When his group is at the post with physical education his level of physical activity is high and emotion is at neutral and positive levels. He even laughs in periods. When they start working with mathematics he opts out of the task at the beginning. During this, he also made negative comments to another pupil. Emotion is neutral. Then he starts working; he becomes more eager, he communicates positively, physical activity increases and emotion becomes positive.

whole day. The curves for leisure time differ from pedagogical time in both variables, though they follow almost the same pattern in the two variables. For leisure 
time, there is a trend of less agitation both indoor and outdoor, except for two of the indoor days.

This positive outcome in behaviour in outdoor education may be caused by the gap between real life and theoretical schedule being filled, making the students more enthusiastic and motivated for the tasks [7,9]. This makes it easier to concentrate on the tasks over time. Since one reason for the disruptive behaviour among young children is the inability to concentrate for a long period of time [3], this method of working will increase civil behaviour. Natural environment may increase attention $[16,60]$. Perhaps it is also connected to the fact that they use their whole body and not only their eyes, ears and brain, and the connection between physical activity and academic learning [40, 42, 61, 62] may give support to this assumption about concentration. The histories from 'Ida' and 'Frank' show a pattern of more time concentrating on tasks when they were at outdoor education and less when they were in the indoor school days. These findings give support to the assumption that the concentration is a mediating variable for agitation.

There is also the possibility that outdoor education has more unstructured time, and, consequently, gives the children more recesses during the day, and the recess may elicit positive behavioural changes [63]. Even when working with academic subjects, outdoor education settings will give room for small recesses when the children are moving from one practical activity to another. Recesses can have a direct influence on decreasing disruptive behaviour [63] and the possibility of engaging in other subjects even for limited moments of time may therefore influence their behaviour. Since the children in this study never reach any high percent of verbal or motor agitation in any condition, the effect might be greater for a group of children that has a relatively high percent of agitation.

\section{Emotion}

The most amazing result is the increased variability in emotions. The outdoor education elicited more joy, smiles and laughter as well as more crying, obvious anger and sadness. Since staying in a natural environment may encourage the children's cooperative behaviour as well as decreasing their disruptive behaviour $[16,36]$, this may lead to increasing engagement and a broader scope of emotional repertoire. The results when the pedagogic time and the leisure time are separated show us that there is a lower percent of neutral emotion during leisure time every day. This occurs in the moments where they are able to, and are supposed to, create their own activity and situation, which probably is more engaging than following the pedagogic activity. The relatively small difference between the outdoor education and the indoor condition during leisure time may be explained by the children's eagerness for doing different activities during their breaks in the traditional school day. The leisure time is only a small part of their day at school in this condition. The environment at this school is relatively wide, open and gives a lot of space for different activities, even though there are many pupils outside together.

\section{Communication}

Outdoor education probably gives access for more verbal communication between the pupils than the indoor condition.
The obvious differences between indoor and outdoor condition considering positive communications for the whole day and for the teaching time, is probably caused by the fact that they were given permission to talk to each other. More interesting is the curve for leisure time that shows almost the same pattern, except for day 4, which is a day with indoor education and a high average level of positive communication. During leisure time, they have the possibility to communicate with each other in both conditions, but outdoor education in this study seems to have the impact of eliciting more positive communication compared with the leisure time in the schoolyard in the indoor condition. This finding could mean that the outdoor situation and/or the environment in this condition elicit more cooperation and communication, which is in accordance with other studies $[10,15,16]$. For negative communication the level is low and no pattern is visible. The increased possibilities for communication during outdoor education can lead to negative communication as well as positive, but the increased crowdedness during indoor education can lead to more aggression and consequently an increased potential for making negative comments $[13,14]$, as well as the fact that the natural environment can broaden the scope for cooperative play and positive communication $[10,15,16]$.

\section{General Discussion}

While the curves for the whole day and for the teaching time follow each other, the curves for leisure time have a different pattern: For all the variables there is less difference between leisure time and pedagogical time in outdoor education as well as the amount of desired and healthy behaviour being higher. This could mean that staying in the natural environment is positive for the children. Another explanation is that the teachers are creative and skilled at organizing pedagogical lessons that go hand in hand with the affordances in the environment. Whether it is mostly the environment or the organization that influences the results for the outdoor condition is therefore hard to say. For the indoor condition, the positive behavioural changes occur going from pedagogic time to leisure time. These changes can have different explanations; first, the change in environment may lead to changed behaviour and second, the changing demands on the children open up for more communication, more physical activity and more individual choices.

The day-to-day stories for 'Ida' and 'Frank' show a trend of combinations between variables: Increased physical activity, positive emotion and positive communication and lack of negative behaviour seem to follow each other. For example, when they are being activated either with a practical task or an increased physical activity, their emotion and communication increases as well, and the negative behaviour is absent. On the other hand, the negative behaviour seems to be connected: If for example the pupil's concentration slips away, restlessness will occur, the potential for performing negative comments increases and agitation may occur. Seeing the large amount of neutral emotion together with other variables may indicate some qualitative differences between the neutral emotion in the classroom and the neutral emotion outside the classroom. The neutral emotion in the classroom has connections with lack of concentration, no communication and restlessness. It 
would seem that the neutral emotion in the classroom is more related to lack of engagement in the situation.

Even though the examples of Ida and Frank are relatively short rather than wide descriptions of the days, they are showing individual ways for reactions on the different conditions. This is in accordance to another study [64] showing different outcomes for subgroups.

\section{LIMITATIONS AND DIRECTIONS FOR FURTHER STUDIES}

A limitation with this study is that only one school is explored. This school has a large schoolyard, in some places without any clear boundaries. This gives the children a wide area to play in, and their schoolyard differs less from their outdoor education environment than will be the case for children in schools that have small schoolyards with gravel and fences. A study including more schools and subjects rather than one school with 12 subjects, would have made it possible to test the significance of the hypotheses rather than exploring the field in this way. Nevertheless, the reversal design in this study makes it possible to explore the field without any control group. Each child is observed intensively in different conditions, making it possible to see the trends of behavioural changes during different school organizations.

Subjective observations are challenging with regard to their reliability, and even though the observers had undergone a learning and agreement procedure and all series were discussed with the first author afterward, there may be some weakness with this kind of observation, especially in the observation with scales. We solved this problem by giving examples and by giving only a small number of possible scores for each variable. Nevertheless, except for the physical activity, which could be measured objectively, the other variables are difficult to ascertain without some kind of subjective observation. The observers have observed the children's behaviour and reactions to changing conditions. Only overt behaviour and expressions are noted, which may make it problematic to say anything about the real emotions within each child. In any case, the overt expressions of emotions are usually connected with the children's real emotions and the atmosphere in the situation.

With randomized phases it is possible to make sure that the phases do not follow any 'natural' units, which can give other variables the possibility of influencing the results [65]. Unfortunately, we were not able to randomize the phases of the interventions in this study, because we did not make the interventions as scientists. We were only following the phases the school was organizing, and anywhere, the outdoor education days will often follow a day-schedule, because it often is a long walk to get to the area. Anyway, the A-phases are somewhat randomized, since the length between the outdoor education days varied. Since the aim of this study was rather to explore the field, than to make a true experiment, following the school time-schedule and not interrupting their plans was a natural choice.

Since our culture seems to afford an increasing amount of sedentary activities, the necessity of a wider variability within teaching conditions will become more important. More studies like this will be needed to explore different effects of this alternative method of outdoor education.
An argument against outdoor education is that too much time is spent on physical activity, play and practical tasks, and as a consequence the time to spend on academic subject is reduced. These alternative activities may be worth something by its own because it is doing something good for the children's development and health [see e.g. [11, 15, 36, 59]] and maybe we should not be so afraid of using some of the academic time to other activities [60-62]. The outdoor education concept should not only be grounded on positive effects in the children's development, but also in academic learning. More studies will therefore be needed to explore more of the learning potentials in outdoor education, as well as to develop good learning methods. These learning outcomes can be hard to state, since the learning process in outdoor education may lead to consolidation of memory both in the cognitive and emotional memory system [6], whereas indoor learning tend to consolidate only in the cognitive memory system which is the kind of learning we usually measures.

\section{CONCLUSION}

Exploring the field of outdoor education is important in order to avoid it becoming an ideology without empirical support. This explorative study shows that outdoor education has many positive behavioural effects such as more physical activity, greater concentration, less restlessness, less verbal and motor agitation, more positive emotions and a larger amount of emotional variability. More studies will be needed to examine these findings further, especially studies with a rigorous methodology and design. However, this study provides a picture of more welfare and healthy development if the children are given the possibility to go to outdoor education occasionally. This will give results that are easily validated and confirmed. However, these results could be used to construct learning benefits for the pupils, e.g. the increased wakefulness and attentiveness should be a subject in further studies, with the aim of developing methods to increase learning outcomes for the pupils. Outdoor education is able to reduce the amount of negative behaviour. This possibility is beneficial for all pupils. First, it is beneficial for the process of socialization and the social learning for children at risk. Secondly, the children nearby are affected by the agitation, since they are disturbed and some are even being threatened or hurt by the agitation.

\section{AUTHORS BIOGRAPHICAL STATEMENT}

Tove Anita Fiskum is a Ph.D. student.

Karl Jacobsen is professor, Dr. psychol.

\section{CONFLICT OF INTEREST}

The authors confirm that this article content has no conflict of interest.

\section{ACKNOWLEDGEMENT}

Declared none.

\section{REFERENCES}

[1] Core Curriculum For Primary, Secondary and Adult Education in Norway. Oslo: Norwegian Board of Education; 2005. Available from: http://www.udir.no/Upload/larerplaner/generell_del/5/Core_ Curriculum_English.pdf? epslanguage $=$ no 
[2] Jordet AN. Klasserommet utenfor: tilpasset opplæring i et utvidet læringsrom. The classroom outside: adjusted teaching in an expanded classroom. Oslo: Cappelen akademisk 2010; p. 395.

[3] Bjorklund DF, Bering JM. The evolved child - Applying evolutionary developmental psychology to modern schooling. Learn Individ Differ 2000; 12(4): 347-73.

[4] Driessnack M. Children and Nature-Deficit Disorder. J Spec Pediatr Nurs 2009; 14(1): 73-5.

[5] Louv R. Last child in the woods: saving our children from naturedeficit disorder. Chapel Hill, NC: Algonquin Books of Chapel Hill 2006; p. 334.

[6] Fiskum TA, Jacobsen K. Outdoor education gives fewer demands for action regulation and an increased variability of affordances. $J$ Adventure Educ Outdoor Learn 2012; 0: 1-24.

[7] Dismore H, Bailey R. "If Only": Outdoor and Adventurous Activities and Generalised Academic Development. J Adventure Educ Outdoor Learn 2005; 5(1): 9-19.

[8] Smith LL, Motsenbocker CE. Impact of hands-on science through school gardening in Louisiana public elementary schools. Hort Technol 2005; 15(3): 439-43.

[9] Canaris I. Growing foods for growing minds: Integrating gardening and nutrition education into the total curriculum. Child Environ 1995; 12(2): 264-70.

[10] Dyment JE. Gaining Ground: The power and Potential of School Ground Greening in the Toronto District School Board 2005: pp.153. Available from: http://www.evergreen.ca/docs/res/Gaining-Gro und.pdf.

[11] Fox P, Avramidis E. An evaluation of an outdoor education programme for students with emotional and behavioural difficulties. Emot Behav Diffic 2003; 8(4): 267-83.

[12] Ozdemir A, Yilmaz O. Assessment of outdoor school environments and physical activity in Ankara's primary schools. J Environ Psychol 2008; 28(3): 287-300.

[13] Murray R. The Influence of crowding on children's behavior. In: Canter D, Lee T, Eds. Psychology and the built environment. Tonbridge, Kent: Architectural Press 1974; pp. 112-7.

[14] Maxwell LE. Multiple effects of home and day care crowding. Environ Behav 1996; 28(4): 494-511.

[15] Dyment JE, Bell AC. Our garden is colour blind, inclusive and warm: reflections on green school grounds and social inclusion. Intl J Inclusive Educ 2008; 12(2): 169-83.

[16] Grahn P. Ute på dagis: hur använder barn daghemsgården? : utformningen av daghemsgården och dess betydelse for lek, motorik och koncentrationsformåga Out at kindergarten: How are the children using their outside environment in kindergarten? Kindergarten environments influence on children's play, motor skills and concentration; in Swedish. Grahn P, Ed. Alnarp: Movium, sekretariatet for den yttre miljøn, Sveriges lantbruksuniversitet 1997; p. 111.

[17] Russell WD, Newton M. Short-term psychological effects of interactive video game technology exercise on mood and attention. Educ Technol Soc 2008; 11(2): 294-308.

[18] Fredrickson BL. The broaden-and-build theory of positive emotions. Philos Trans R Soc Lond Sr B Biol Sci 2004; 359(1449): 1367-77.

[19] Waring M, Warburton P, Coy M. Observation of children's physical activity levels in primary school: Is the school an ideal setting for meeting government activity targets? Eur Phys Educ Rev 2007; 3(1): 25-40.

[20] McKenzie TL, Sallis JF, Prochaska JJ, Conway TL, Marshall SJ, Rosengard P. Evaluation of a two-year middle-school physical education intervention: M-SPAN. Medicine Sci Sports Exer 2004; 36(8): 1382-8.

[21] Bell JF, Wilson JS, Liu GC. Neighborhood greenness and 2-year changes in body mass index of children and youth. Am J Prevent Med 2008; 35(6): 547-53.

[22] Nyberg GA, Nordenfelt AM, Ekelund U, Marcus C. Physical Activity Patterns Measured by Accelerometry in 6-to 10-yr-Old Children. Med Sci Sports Exerc 2009; 41(10): 1842-8.

[23] Dale D, Corbin CB, Dale KS. Restricting opportunities to be active during school time: Do children compensate by increasing physical activity levels after school? Res Q Exerc Sport 2000; 71(3): 240-8.

[24] Gibson JJ. The ecological approach to visual perception. Hillsdale: Lawrence Erlbaum 1986; pp. 127-43.
[25] Fjortoft I, Sageie J. The natural environment as a playground for children - Landscape description and analyses of a natural playscape. Landscape Urban Plann 2000; 48(1-2): 83-97.

[26] Boldemann C, Blennow M, Dal H, et al. Impact of preschool environment upon children's physical activity and sun exposure. Prevent Med 2006; 42(4): 301-8.

[27] Mygind E. A Comparison between children's physical activity levels at school and learning in an outdoor environment. J Adventure Educ Outdoor Learn 2007; 7(2): 161-76.

[28] Resaland GK, Mamen A, Anderssen SA, Andersen LB. Cardiorespiratory fitness and body mass index values in 9-year-old rural Norwegian children. Acta Paediatrica 2009; 98(4): 687-92.

[29] Moller NC, Kristensen PL, Wedderkopp N, Andersen LB, Froberg K. Objectively measured habitual physical activity in $1997 / 1998$ vs 2003/2004 in Danish children: The European Youth Heart Study. Scand J Med Sci Sports 2009; 19(1): 19-29.

[30] Dencker M, Thorsson O, Karlsson MK, Linden C, Wollmer P, Andersen LB. Daily physical activity related to aerobic fitness and body fat in an urban sample of children. Scand J Med Sci Sports 2008; 18(6): 728-35.

[31] Bailey D. Is anyone out there listening? Quest. 2000; 52(4): 34450 .

[32] Andersen REP, Crespo CD, Bartlett SJP, Pratt MMD. Television Watching and Fatness in Children. JAMA 1998; 280(14): 1230-1.

[33] Cradock AL, Melly SJ, Allen JG, Morris JS, Gortmaker SL. Characteristics of school campuses and physical activity among youth. Am J Prevent Med 2007; 33(2): 106-13.

[34] Harten N, Olds T, Dollman J. The effects of gender, motor skills and play area on the free play activities of 8-11 year old school children. Health Place 2008; 14(3): 386-93.

[35] Zask A, van Beurden E, Barnett L, Brooks LO, Dietrich UC. Active school playgrounds - Myth or reality? Results of the "move it groove it" project. Prevent Med 2001; 33(5): 402-8

[36] Dyment JE, Bell AC. Grounds for movement: green school grounds as sites for promoting physical activity. Health Educ Res 2008; 23(6): 952-62.

[37] Sallis JF, Conway TL, Prochaska JJ, McKenzie TL, Marshall SJ, Brown M. The association of school environments with youth physical activity. Am J Public Health 2001; 91(4): 618-20.

[38] Haug E, Torsheim T, Samdal O. Physical environmental characteristics and individual interests as correlates of physical activity in Norwegian secondary schools: the health behaviour in school-aged children study. Int J Behav Nutr Phys Act 2008; 5: 47.

[39] Kulinna PH, Brusseau T, Cothran D, Tudor-Locke C. Changing school physical activity: an examination of individual school designed programs. J Teach Phys Educ 2012; 31(2): 113-30.

[40] Etnier JL, Salazar W, Landers DM, Petruzzello SJ, Han M, Nowell $\mathrm{P}$. The influence of physical fitness and exercise upon cognitive functioning: A meta-analysis. J Sport Exerc Psychol 1997; 19(3): 249-77.

[41] Sibley BA, Etnier JL. The relationship between physical activity and cognition in children: a meta-analysis. Pediatr Exerc Sci 2003 15(3): 243-56.

[42] Hillman CH, Erickson KI, Kramer AF. Be smart, exercise your heart: exercise effects on brain and cognition. Nat Rev Neurosci 2008; 9(1): 58-65.

[43] Tomporowski PD, Davis CL, Miller PH, Naglieri JA. Exercise and children's intelligence, cognition, and academic achievement. Educ Psychol Rev 2008; 20(2): 111-31.

[44] Hughes C. Introduction - Executive functions and development: Why the interest? Infant Child Devel 2002; 11(2): 69-71.

[45] Jacobsen K, Svendsen B. Emosjonsregulering og oppmerksomhet: grunnfenomener i terapi med barn og unge Emotion-regulation and attention: Basic phenomenon in therapy with children and youth. Bergen: Fagbokforlaget 2010; p. 270s.

[46] Campos JJ, Frankel CB, Camras L. On the nature of emotion regulation. Child Dev 2004; 75(2): 377-94.

[47] Jacobsen K, Bjerkan B, Sørlie R. Challenging behaviour in an adult with congenital deaf-blindness. Scand J Disabil Res 2009; 11(3): 209-20.

[48] Panksepp J, Burgdorf J, Turner C, Gordon N. Modeling ADHDtype arousal with unilateral frontal cortex damage in rats and beneficial effects of play therapy. Brain Cogn 2003; 52(1): 97-105.

[49] Panksepp J. Neuroevolutionary sources of laughter and social joy: Modeling primal human laughter in laboratory rats. Behav Brain Res 2007; 182(2): 231-44. 
[50] Panksepp J. The quest for long-term health and happiness: To play or not to play, that is the question. Psychol Inq 1998; 9(1): 56-66.

[51] Panksepp J, Burgdorf J. "Laughing" rats and the evolutionary antecedents of human joy? Physiol Behav 2003; 79(3): 533-47.

[52] Rahm J. Emergent learning opportunities in an inner-city youth gardening program. J Res Sci Teach 2002; 39(2): 164-84.

[53] Alexander J, North M-W, Hendren DK. Master gardener classroom garden project: an evaluation of the benefits to children. Child Environ 1995; 12(2): 256-63.

[54] Ballantyne R, Packer J. Introducing a fifth pedagogy: experiencebased strategies for facilitating learning in natural environments. Environ Educ Res 2009; 15(2): 243-62.

[55] Rickinson M, Dillon J, Teamey K, et al. A review of Research on Outdoor Learning 2004. Available from: http://www.field-studiescouncil.org/documents/general/NFER/A_review_of_research_on_o utdoor learning.pdf

[56] Hopkins B, Beek PJ, Kalverboer AF, Eds. Motor development in early and later childhood: longitudinal approaches. Cambridge: Cambridge University Press 1993.

[57] Thomas JR, Nelson JK. Research methods in physical activity. Champaign: Human Kinetics 2001; pp. 309-21.

[58] Sarafino EP. Principles of Behavior Change. USA: John Wiley \& Sond, Inc 1996.
[59] Bell AC, Dyment JE. Grounds for Health: The Intersection of green school grounds and health-promoting schools. Environ Educ Res 2008; 14(1): 77-90.

[60] Berman MG, Jonides J, Kaplan S. The cognitive benefits of interacting with nature. Psychol Sci 2008; 19(12): 1207-12.

[61] Ahamed Y, MacDonald H, Reed K, Naylor PJ, Liu-Ambrose T, McKay H. School-based physical activity does not compromise children's academic performance. Med Sci Sports Exerc 2007; 39(2): 371-6.

[62] Trudeau F, Shephard RJ. Physical education, school physical activity, school sports and academic performance. Int J Behav Nutr Physical Activ 2008; 5: 10.

[63] Ridgway A, Northup J, Pellegrin A, Larue R, Hightshoe A. Effects of recess on the classroom behavior of children with and without attention-deficit hyperactivity disorder. School Psychol Quart 2003; 18(3): 253-68.

[64] Fiskum TA, Jacobsen K. Individual differences and possible effects from outdoor education: long time and short time benefits. World J Educ 2012; 2(4): 20-33.

[65] Wagenaar RC. Functional Recovery After Stroke. Amsterdam, VU: University Press 1990.

(C) Fiskum and Jacobsen; Licensee Bentham Open.

This is an open access article licensed under the terms of the Creative Commons Attribution Non-Commercial License (http://creativecommons.org/licenses/by-nc/3.0/) which permits unrestricted, non-commercial use, distribution and reproduction in any medium, provided the work is properly cited. 